\title{
20(S)-ginsenoside Rg3 inhibits glycoprotein IIb/IIIa activation in human platelets
}

\author{
Hyuk-Woo Kwon ${ }^{1}$
}

Received: 21 June 2018 / Accepted: 15 August 2018 / Published Online: 30 September 2018

(C) The Korean Society for Applied Biological Chemistry 2018

\begin{abstract}
The Panax ginseng Mayer is used in conventional medicine in Asia owing to its preventing effects on thrombosis, hypertension, atherosclerosis, vasorelaxation and myocardial infarction. Because platelets are crucial mediators of cardiovascular diseases, many studies have investigated its functions. The previous study showed the antiplatelet effects of crude ginseng fraction and two of its components, ginsenoside $\mathrm{Rg} 3$ (20S and 20R). In addition, ginsenoside $\mathrm{Rg} 3$-enriched fraction shows an inhibitory effect on collagen-activated rat platelets. However, the mechanism underlying this effect remains unclear. Thus, I investigated the inhibitory action of ginsenoside Rg3 (20S, G$\mathrm{Rg} 3)$ on the regulation of signaling molecules involved in $\alpha \mathrm{Ilb} / \beta_{3}$ activation. I found that G-Rg3, in a cyclic AMP dependent manner, inhibited thrombin-induced activation of human platelets and affinity of fibrinogen and fibronectin with $\alpha \mathrm{IIb} / \beta_{3}$. Thus, in the present study, G-Rg3 showed an inhibitory effect on glycoprotein IIb/IIIa $\left(\alpha \mathrm{IIb} / \beta_{3}\right)$ activation, suggesting its potential use for preventing platelet-mediated thrombotic disease.
\end{abstract}

Keywords 20(S)-ginsenoside $\operatorname{Rg} 3$ - Clot retraction · Cyclic AMP $\cdot$ Fibrinogen $\cdot$ Fibronectin

\section{Introduction}

Platelets are activated at a site of vascular damage by adenosine

Hyuk-Woo Kwon $(\bowtie)$

E-mail:kwonhw@kdu.ac.kr

${ }^{1}$ Department of Biomedical Laboratory Science, Far East University, Eumseong 27601, Republic of Korea

This is an Open Access article distributed under the terms of the Creative Commons Attribution Non-Commercial License (http://creativecommons. org/licenses/by-nc/3.0/) which permits unrestricted non-commercial use, distribution, and reproduction in any medium, provided the original work is properly cited. diphosphate, collagen and thrombin. Platelet aggregation is important for the maintenances of normal hemostasis. Platelet activation and platelet aggregation are due to the action of glycoprotein IIb/IIIa $\left(\alpha \mathrm{IIb} / \beta_{3}\right)$. The $\alpha \mathrm{II} b / \beta_{3}$ located on platelet surface binds with plasma proteins such as fibrinogen, fibronectin, thrombospondin, and vitronectin, causing $\mathrm{Ca}^{2+}$ mobilization, shape change, degranulation [1], and ultimately thrombus formation.

In normal circulation, vascular endothelial cells release both prostaglandin $\mathrm{I}_{2}$ and nitric oxide, which facilitate the 3',5'-cyclic adenosine monophosphate (cyclic AMP) and 3' 5'-cyclic guanosine monophosphate (cyclic GMP) synthesis. Elevated cyclic AMP and cyclic GMP levels induce the protein kinase A (PKA) and protein kinase $\mathrm{G}(\mathrm{PKG})$, respectively, which downregulate platelet functions [2]. Vasodilator-stimulated phosphoprotein (VASP) is a major substrate of PKA and PKG in the platelet. VASP supports the regulation of actin filament dynamics and $\alpha \mathrm{IIb} / \beta_{3}$ activation, but VASP Ser ${ }^{157}$ phosphorylation or VASP Ser ${ }^{239}$ phosphorylation leads to the inhibition of actin filament elongation and suppression of $\alpha \mathrm{Ilb} / \beta_{3}$ activation $[3,4]$. $\alpha \mathrm{IIb} / \beta_{3}$ the most abundant binding molecule on the platelet surface, is important in the formation of fibrin-platelet mesh and in the interaction between platelet and monocytes. Activated $\alpha \mathrm{IIb} / \beta_{3}$ undergoes a rapid shape change allowing the platelet membrane to bind to vascular adhesion molecules. Therefore, VASP phosphorylation could be used to examine the anti-thrombotic effect of a compound.

G-Rg3 suppresses blood platelet aggregation [5], thromboxane $\mathrm{A}_{2}$ release, $\left[\mathrm{Ca}^{2+}\right]_{\mathrm{i}}$ mobilization and ATP release [6]. Furthermore, an $\operatorname{Rg} 3$ derivative, dihydroxyginsenoside $\mathrm{Rg} 3$, decreases mitogenactivated protein kinases [7]. Rg3-enriched fraction also shows inhibitory effects on collagen-induced rat platelets [8]. In previous report, I confirmed the inhibitory action of G-Rg3 on thrombinactivated platelets [9]. However, the suppressive mechanism on the platelets is not fully understood. Therefore, in the present investigation, I characterized the modulatory mechanism of G$\operatorname{Rg} 3$ on human platelet $\alpha \mathrm{IIb} / \beta_{3}$. 


\section{Materials and Methods}

\section{Materials}

I purchased 20(S)-ginsenoside Rg3 from the Ambo Institute (Daejon, Korea). Human fibrinogen connected-Alexa Flour 488 was purchased from Invitrogen Molecular Probes (Eugene, OR, USA). I purchased thrombin and all materials for platelet aggregation from Chrono-Log (Havertown, PA, USA) and purchased eptifibatide, GR 144053, anti-rabbit IgG-HRP, antibeta-actin from Santa Cruz (Santa Cruz, CA, USA). The cyclic AMP and cyclic GMP EIA kits were purchased from Cayman (Ann Arbor, MI, USA). I purchased all materials for buffer solution and Rp-8-Br-cAMPS, pCPT-cAMP, 8-Br-cGMP from Sigma (St. Louis, MO, USA). Antibodies for Western blotting such as Anti-VASP, anti-phosphor-VASP ( $\left.\mathrm{Ser}^{157}, \mathrm{Ser}^{239}\right)$, and lysis buffer were purchased from Cell Signaling (Beverly, MA, USA)., and the Cell Adhesion Assay (Colorimetric Format) Kit were purchased from Cell Biolabs (San Diego, CA, USA).

\section{Preparation of washed human platelets}

Human platelet rich plasma (PRP) was obtained from the Korean Red Cross Blood Center (Changwon, Korea). The PRP centrifuged for $10 \mathrm{~min}$ at $1,300 \times \mathrm{g}$ and the platelet-containing pellets were washed twice with washing buffer solution $(138 \mathrm{mM} \mathrm{NaCl}, 2.7$ $\mathrm{mM} \mathrm{KCl}, 12 \mathrm{mM} \mathrm{NaHCO} 3,0.36 \mathrm{mM} \mathrm{NaH}_{2} \mathrm{PO}_{4}, 5.5 \mathrm{mM}$ glucose, and $1 \mathrm{mM} \mathrm{Na} \mathrm{m}_{2}$ EDTA, $\mathrm{pH}$ 6.5), and resuspended in suspension buffer solution $(138 \mathrm{mM} \mathrm{NaCl}, 2.7 \mathrm{mM} \mathrm{KCl}, 12 \mathrm{mM} \mathrm{NaHCO}$, $0.36 \mathrm{mM} \mathrm{NaH} \mathrm{PO}_{4}, 0.49 \mathrm{mM} \mathrm{MgCl}_{2}, 5.5 \mathrm{mM}$ glucose, $0.25 \%$ gelatin, $\mathrm{pH}$ 6.9). The platelet concentration was adjusted to a final concentration of $5 \times 10^{8} / \mathrm{mL}$. All procedures for platelet suspension were performed at $25^{\circ} \mathrm{C}$. Experimental approval (PIRB12-072) was obtained from the Public Institutional Review Board at the National Institute for Bioethics Policy (Seoul, Korea).

\section{Measurement of platelet aggregation}

Washed human platelets $\left(10^{8} / \mathrm{mL}\right)$ were preincubated with various concentrations of G-Rg3 in $2 \mathrm{mM} \mathrm{CaCl}_{2}$ for 2 min at $37^{\circ} \mathrm{C}$ and then facilitated by thrombin $(0.05 \mathrm{U} / \mathrm{mL})$. The platelet aggregation assay was conducted for $5 \mathrm{~min}$ and the aggregation percentage was determined as an increase in light transmission. G-Rg3 was dissolved in $0.1 \%$ dimethyl sulfoxide (DMSO).

\section{Measurement of cyclic AMP and cyclic GMP concentration} Platelet aggregation with various concentrations of G-Rg3 was terminated by adding $80 \%$ ethanol to the platelet suspension. Next, cyclic nucleotides were extracted three times from the suspension by using $80 \%$ ethanol, and were dried by nitrogen gas. The dried pellet was dissolved in an assay buffer from a cyclic AMP/GMP EIA kit. The cyclic AMP and cyclic GMP concentration was determined using Synergy HT Multi-Model Microplate Reader (BioTek Instruments, Winoosku, VT, USA).

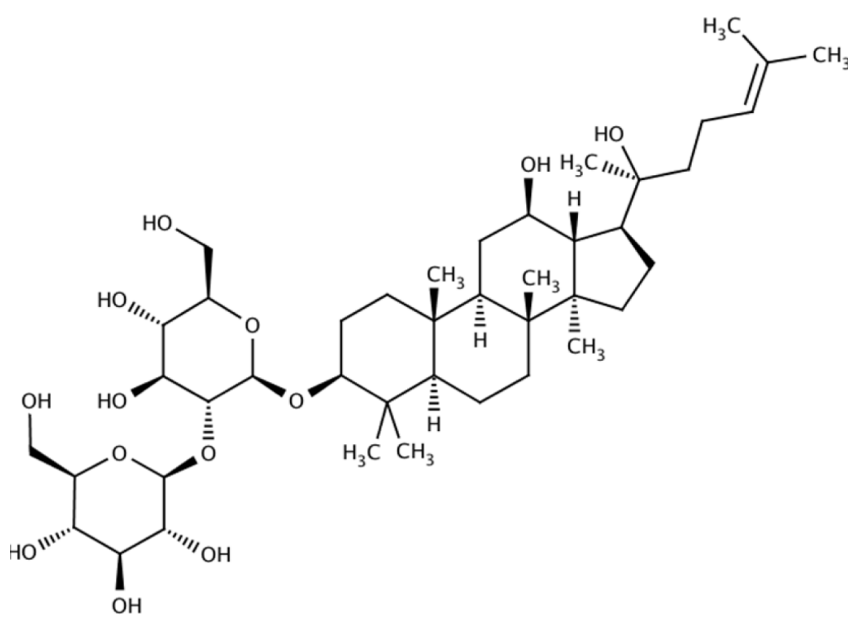

Fig. 1 Chemical structure of 20(S)-ginsenoside Rg3. Ginsenoside Rg3 contained in Panax ginseng Meyer

\section{Measurement of VASP-phosphorylation}

Platelet aggregation with various concentrations of G-Rg3 was stopped and dissolved by $1 \times$ lysis buffer. The platelet lysates were adjusted to $15 \mu \mathrm{g}$ of protein for Western blot using a BCA protein assay kit (Pierce Biotechnology, Rockford, IL, USA). The protein samples were separated through 6\% SDS-PAGE, and transferred onto PVDF membranes. The dilutions for the primary and secondary antibodies were 1:1,000 and 1:10,000, respectively. The protein bands were visualized using the ECL reagent (General Electric Healthcare, Buckinghamshire, UK).

\section{Measurement of fibrinogen binding to $\alpha \mathrm{IIb} / \beta_{3}$}

The platelet aggregation assay was conducted with various concentrations of G-Rg3 in the presence of human fibrinogen (30 $\mu \mathrm{g} / \mathrm{mL}$ ) connected Alexa Flour 488 . The platelets were fixed by adding $0.5 \%$ paraformaldehyde in PBS and all procedures were conducted in darkness. The fibrinogen binding assay was conducted by a flow cytometry (BD Biosciences, San Jose, CA, USA).

\section{Measurement of fibronectin adhesion}

The adhesion kit is coated with fibronectin or, as a negative control, bovine serum albumin (BSA). Washed platelets $\left(10^{8} / \mathrm{mL}\right)$ were preincubated on the plates for $60 \mathrm{~min}$ at $37^{\circ} \mathrm{C}$ in the presence of thrombin $(0.05 \mathrm{U} / \mathrm{mL})$ and various concentrations of $\mathrm{G}-\mathrm{Rg} 3$. Next, the plates were washed three times with PBS, and incubated with cell staining solution at RT for $10 \mathrm{~min}$. The platelets were washed again, extraction solution was used. Fibronectin adhesion was measured using Synergy HT Multi-Model Microplate Reader (BioTek Instruments, Winooski, VT, USA).

Measurement of platelet-mediated fibrin clot retraction Human PRP $(250 \mu \mathrm{L})$ was preincubated in a tube with G-Rg3 
$(300 \mu \mathrm{M})$ for $10 \mathrm{~min}$ at $37^{\circ} \mathrm{C}$, and facilitated by $0.05 \mathrm{U} / \mathrm{mL}$ of thrombin. Clot pictures were taken at $15 \mathrm{~min}$, and Clot area was calculated using the Image J Software. The percentage of clot retraction was calculated as follows: Retraction (\%) by thrombin $=($ basal area - thrombin area $) /$ basal area $\times 100$.

\section{Statistical analyses}

Experimental data are indicated as the mean \pm standard deviation accompanied by the number of observations. Significant differences among the groups were determined by analysis of variance (ANOVA) and further analyzed by using the Newman-Keuls method. Statistical analysis was performed by using SPSS 21.0.0.0 software (SPSS, Chicago, IL, USA). $p<0.05$ was considered as statistically significant.

\section{Results}

\section{Inhibitory action of G-Rg3 on platelet aggregation}

In previous report, thrombin at $0.05 \mathrm{U} / \mathrm{mL}$ induces the optimum aggregation of human platelets [9]. In present study, the aggregation rate of thrombin induced platelets was $91.5 \pm 1.3 \%$ (Fig. 2). However, the aggregation rates of platelets treated with G-Rg3 $(50,100,200$, and $300 \mu \mathrm{M})$ were significantly reduced (inhibitory degrees were $15.7,38.1,74.7$, and $88.2 \%$, respectively), indicating that G-Rg3 inhibited the platelet aggregation in a dosedependent manner. DMSO 0.1\% did not influence the aggregation (Fig. 2).

\section{Inhibitory action of G-Rg3 on cyclic AMP and cyclic GMP concentration}

Next, $\underline{I}$ investigated the cyclic AMP and cyclic GMP concentration by G-Rg3 during platelet aggregation. During thrombin-stimulated platelet aggregation, G-Rg3 $(300 \mu \mathrm{M})$ increased cyclic AMP concentration but did not affect the cyclic GMP concentration (Table 1).

\section{Inhibitory action of G-Rg3 on VASP-phosphorylation}

Following phosphorylation, the molecular mass of VASP shifted from 46 to $50 \mathrm{kDa}[9,10]$. As G-Rg3 showed a dose-dependent inhibitory effect on agonist-induced platelet aggregation (Fig. 2), I further investigated the effect of G-Rg3 on VASP $\left(\operatorname{Ser}^{157}, \mathrm{Ser}^{239}\right)$ phosphorylation in human platelets. G-Rg3 significantly increased VASP $\operatorname{Ser}^{157}$ phosphorylation (Fig. 3A) in a dose-dependent

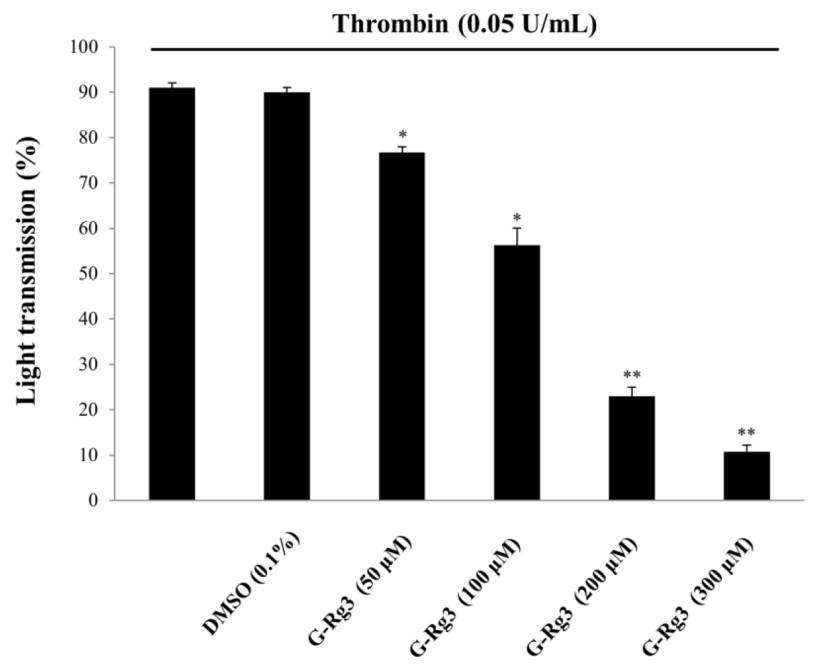

Fig. 2 Inhibitory effects of G-Rg3 on thrombin-induced human platelet aggregation. Measurement of platelet aggregation and cytotoxicity were described in "Materials and Methods" section. $0.1 \%$ Triton X-100 was treated to platelets as a positive control. The data are expressed as the mean \pm standard deviation $(n=4)$. NS, not significant versus without G$\mathrm{Rg} 3$, control. The data are expressed as the mean \pm standard deviation $(\mathrm{n}=4) .{ }^{*} p<0.05$ versus the thrombin-stimulated human platelets

manner. On the contrary, G-Rg3 did not affect VASP Ser $^{239}$ phosphorylation (Fig. 3B) suggesting that G-Rg3 did not affect cyclic GMP level (Table 1). Since G-Rg3 stimulated cyclic AMP level (Table 1), I hypothesized that G-Rg3-elevated VASP Ser ${ }^{157}$ phosphorylation may be inhibited by Rp-8-Br-cAMPS, a A-kinase inhibitor. To test this hypothesis, I examined the effect of Rp-8-BrcAMPS on G-Rg3 (300 $\mu \mathrm{M})$-induced VASP Ser ${ }^{157}$ phosphorylation. The Rp-8-Br-cAMPS significantly decreased G-Rg3-induced VASP Ser $^{157}$ phosphorylation, whereas the pCPT-cAMP, a Akinase activator, increased VASP $\mathrm{Ser}^{157}$ phosphorylation (Fig. 3C). These results indicated the involvement of elevated cyclic AMP level in G-Rg3-induced VASP Ser ${ }^{157}$ phosphorylation.

\section{Inhibitory action of G-Rg3 on binding between fibrinogen and $\alpha \mathbf{I I b} / \beta_{3}$}

Since G-Rg3 increased VASP phosphorylation (Fig. 3A), I examined the binding affinity fibrinogen with $\alpha \mathrm{IIb} / \beta_{3}$ in human platelets using G-Rg3. Thrombin increased the binding between fibrinogen and $\alpha \mathrm{IIb} / \beta_{3}$ (Fig. $4 \mathrm{~A}-\mathrm{b}, 4 \mathrm{~B}$ ), with a rate of $94.8 \pm 0.5 \%$ (Table 2) but, G-Rg3 decreased the binding affinity of fibrinogen with $\alpha \mathrm{IIb} / \beta_{3}$ (Fig. 4A-d $\sim$ g, 4B), with an inhibitory degree of

Table 1 Inhibitory effects of G-Rg3 on cyclic AMP and cyclic GMP

\begin{tabular}{ccccc}
\hline \hline & cyclic AMP $\left(\mathrm{pmoL} / 10^{8}\right.$ platelets $)$ & $\Delta(\%)$ & cyclic GMP $\left(\mathrm{pmoL} / 10^{8}\right.$ platelets $)$ & $\Delta(\%)$ \\
\hline Thrombin $(0.05 \mathrm{U} / \mathrm{mL})$ & $4.6 \pm 0.3$ & - & $3.0 \pm 0.1$ & - \\
+ DMSO $0.1 \%$ & $5.8 \pm 0.3$ & 24.9 & $2.2 \pm 0.1$ & 26.7 \\
+ G-Rg3 $(300 \mu \mathrm{M})$ & $11.3 \pm 0.1$ & 145.2 & $2.2 \pm 0.1$ & 26.7 \\
\hline
\end{tabular}

$\Delta(\%)=[$ (thrombin $+\mathrm{G}-\mathrm{Rg} 3-$ thrombin $]$ /thrombin $\times 100$. The data are expressed as the mean \pm standard deviation $(\mathrm{n}=4)$ 
(1)

Thrombin (0.05 U/mL)

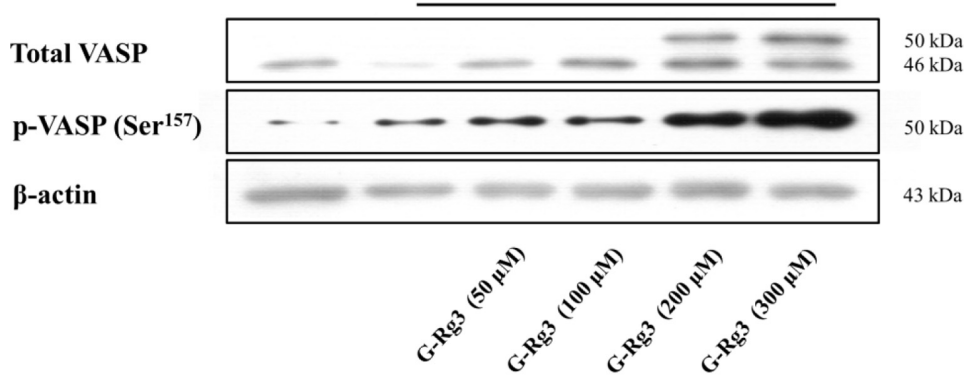

(B)

Thrombin $(0.05 \mathrm{U} / \mathrm{mL})$

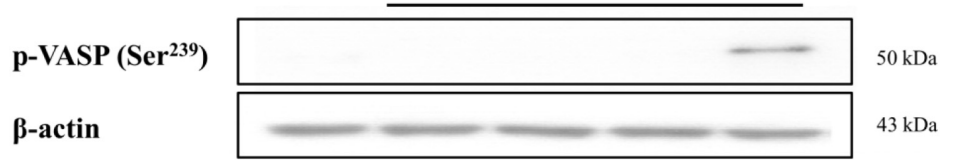

(C)
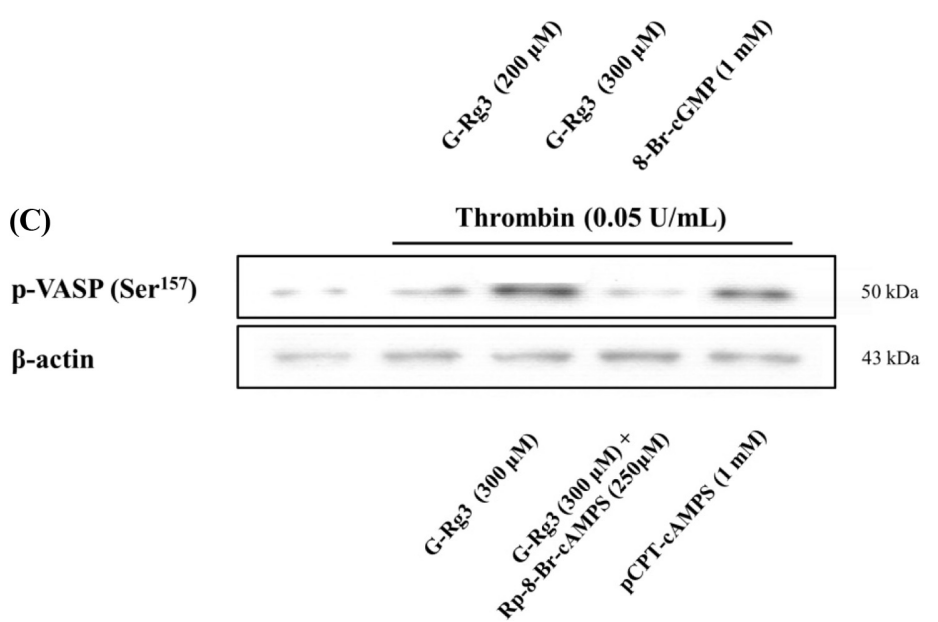

Fig. 3 Inhibitory effects of G-Rg3 on VASP phosphorylation. (A) Effects of G-Rg3 on VASP phosphorylation. (B) Effects of G-Rg3 on VASP (Ser ${ }^{239}$ )$50 \mathrm{kDa}$ phosphorylation. (C) Effects of G-Rg3 on VASP $\left(\mathrm{Ser}^{157}\right)-50 \mathrm{kDa}$ phosphorylation in the presence of Rp-8-Br-cAMPS. Measurement of Western blotting was described in "Materials and Methods" section. The data are expressed as the mean \pm standard deviation ( $\mathrm{n}=4$ )

81.4\% (Table 2). The eptifibatide and GR 144053, $\alpha \mathrm{IIb} / \beta_{3}$ inhibitors, were used as a positive control and inhibited thrombininduced affinity of fibrinogen with $\alpha \mathrm{IIb} / \beta_{3}$ (Fig. 4A-h, i, 4B), with inhibitory degrees of 59.5 and $62.3 \%$, respectively. Moreover, I

Table 2 Inhibitory effects of G-Rg3 on changes of fibrinogen binding

\begin{tabular}{lcc}
\hline \hline & Fibrinogen Binding $(\%)$ & $\Delta(\%)$ \\
\hline Intact platelets & $8.1 \pm 0.3$ & - \\
Thrombin $(0.05 \mathrm{U} / \mathrm{mL})$ & $94.8 \pm 0.5$ & - \\
G-Rg3 $(300 \mu \mathrm{M})$ & $17.6 \pm 1.9$ & $-81.4^{1)}$ \\
$\quad+$ Thrombin $(0.05 \mathrm{U} / \mathrm{mL})$ & & \\
G-Rg3 $(300 \mu \mathrm{M})$ & $47.7 \pm 0.7$ & $+171.0^{2)}$ \\
$\quad+$ Thrombin $(0.05 \mathrm{U} / \mathrm{mL})$ & & \\
+ Rp-8-Br-cAMPS $(250 \mu \mathrm{M})$ & & \\
\hline
\end{tabular}

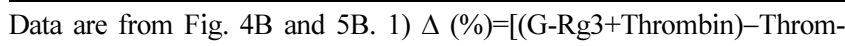
$\mathrm{bin}] /$ Thrombin $\times 100.2) \Delta(\%)=[(\mathrm{G}-\mathrm{Rg} 3+$ Thrombin+Rp-8-Br-cAMPS $)$ (G-Rg3+Thrombin)]/(G-Rg3+Thrombin) $] \times 100$ tested the effect of Rp-8-Br-cAMPS, an A-kinase inhibitor, on G$\mathrm{Rg} 3$-suppressed the affinity of fibrinogen with $\alpha \mathrm{IIb} / \beta_{3}$. The Rp-8Br-cAMPS increased G-Rg3-reduced the affinity (Fig. 4A-a, 4B) with an inhibitory degree of $171.0 \%$ higher than that of G-Rg3 $(300 \mu \mathrm{M})$ alone $(17.6 \pm 1.9 \%)$ (Table 2$)$.

\section{Inhibitory action of G-Rg3 on adhesion between fibronectin and $\alpha \mathbf{I I b} / \beta_{3}$}

The integrin $\alpha \mathrm{Ilb} / \beta_{3}$ on platelet surface served as a receptor for platelet adhesion. I examined whether G-Rg3 suppressed fibronectin adhesion to $\alpha \mathrm{Ilb} / \beta_{3}$. The platelets did not adhere to BSA coated well, but adhered to fibronectin coated well under thrombin stimulation. G-Rg3 (50 to $300 \mu \mathrm{M}$ ) decreased fibronectin adhesion to $\alpha \mathrm{IIb} / \beta_{3}$ dose-dependent manner. Moreover, eptifibatide and GR 144053, $\alpha \mathrm{IIb} / \beta_{3}$ inhibitors, attenuated fibronectin adhesion to $\alpha \mathrm{IIb} / \beta_{3}$ as a positive control. Next, I investigated whether G-Rg3 inhibited $\alpha \mathrm{Il} b / \beta_{3}$ adhesion to fibronectin by increasing cyclic AMP 

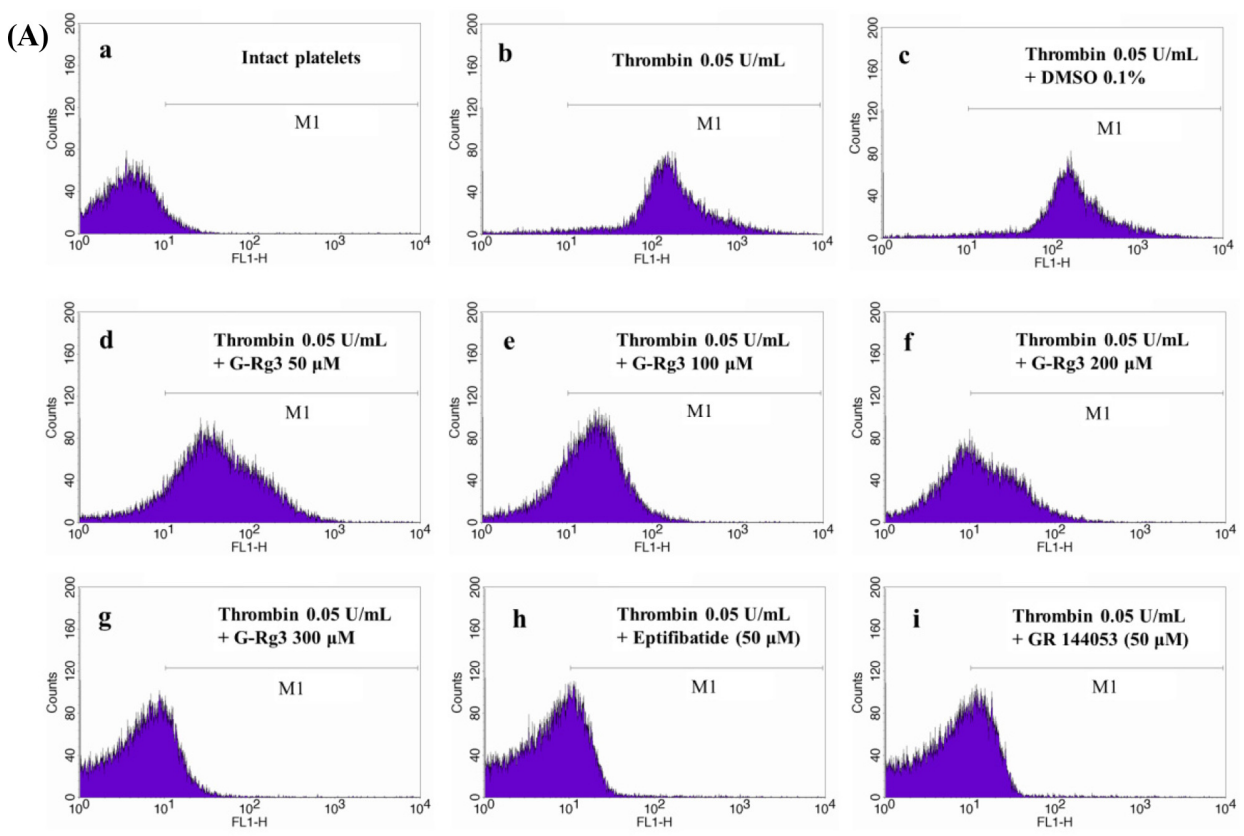

(B)

Thrombin (0.05 U/mL)

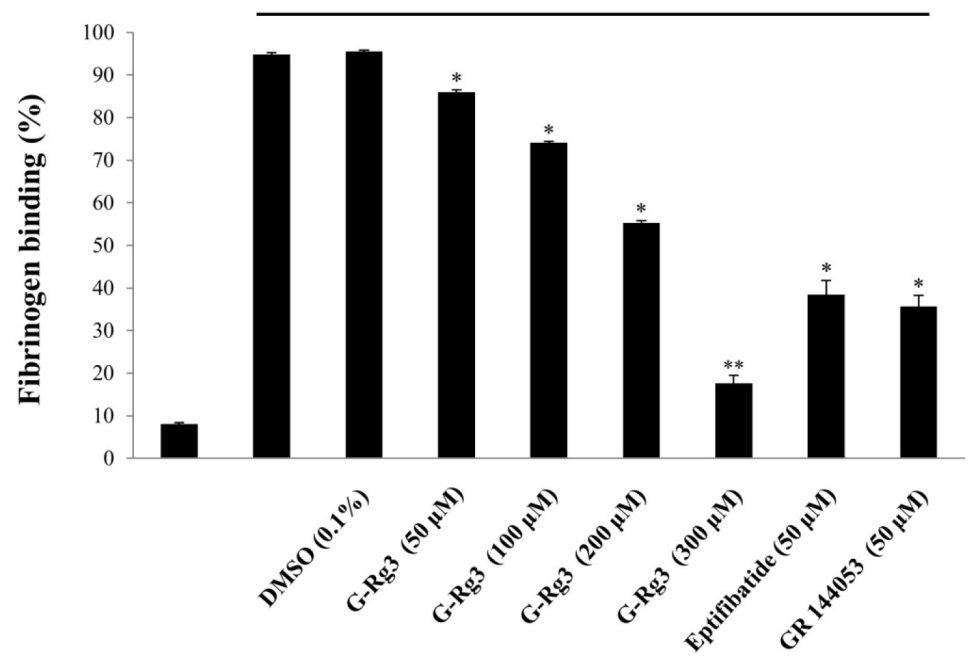

Fig. 4 Inhibitory effects of G-Rg3 on thrombin-induced fibrinogen binding. (A) The flow cytometry histograms on fibrinogen binding. a, Intact platelets (base); b, Thrombin (0.05 U/mL); c, Thrombin (0.05 U/mL) + DMSO (0.1\%); d, Thrombin $(0.05 \mathrm{U} / \mathrm{mL})+\mathrm{G}-\mathrm{Rg} 3(50 \mu \mathrm{M})$; e, Thrombin $(0.05$ $\mathrm{U} / \mathrm{mL})+\mathrm{G}-\mathrm{Rg} 3(100 \mu \mathrm{M})$; f, Thrombin $(0.05 \mathrm{U} / \mathrm{mL})+\mathrm{G}-\mathrm{Rg} 3(200 \mu \mathrm{M})$; g, Thrombin $(0.05 \mathrm{U} / \mathrm{mL})+\mathrm{G}-\mathrm{Rg} 3(300 \mu \mathrm{M})$; h, Thrombin $(0.05 \mathrm{U} /$ $\mathrm{mL})+$ eptifibatide $(50 \mu \mathrm{M})$; i, Thrombin $(0.05 \mathrm{U} / \mathrm{mL})+\mathrm{GR} 144053(50 \mu \mathrm{M})$. (B) Effects of G-Rg3 on thrombin-induced fibrinogen binding (\%). Measurement of fibrinogen binding was described in "Materials and Methods section". The data are expressed as the mean \pm standard deviation $(\mathrm{n}=4)$. ${ }^{*} p<0.05$ versus the thrombin-stimulated human platelets

level. The Rp-8-Br-cAMPS increased G-Rg3-induced inhibition of fibronectin adhesion to $\alpha \mathrm{IIb} / \beta_{3}$ (Fig. 6B). Moreover, the pCPTcyclic AMP also inhibited fibronectin adhesion to $\alpha \mathrm{Ilb} / \beta_{3}$ (Fig. $6 \mathrm{~B}$ ), indicating that the elevated cyclic AMP concentration involved in the adhesion action.

\section{Inhibitory action of G-Rg3 on fibrin clot retraction}

The activation of $\alpha \mathrm{IIb} / \beta_{3}$ by platelet agonists increased the affinity of fibrinogen and fibronectin with $\alpha \mathrm{IIb} / \beta_{3}$ leading to the outside- in $\alpha \mathrm{IIb} / \beta_{3}$ signaling and containing clot retraction. Thus I investigated the effect of G-Rg3 on the retraction of thrombin-induced fibrin clots, an index of outside-in $\alpha \mathrm{Ilb} / \beta_{3}$ signaling. In Fig. 7A shows result showed that thrombin stimulated fibrin clot formation and retraction. In Fig. 7B, thrombin potently increased fibrin clot retraction, and this increase was $90 \%$ higher than that observed without thrombin $\left(55 \pm 1.3 \mathrm{~mm}^{2}\right)$. However, G-Rg3 attenuated fibrin clot retraction, and its percentage was $664 \%$ as compared with thrombin stimulated fibrin clot retraction $\left(22 \pm 1.1 \mathrm{~mm}^{2}\right)$ (Fig. 7B). 

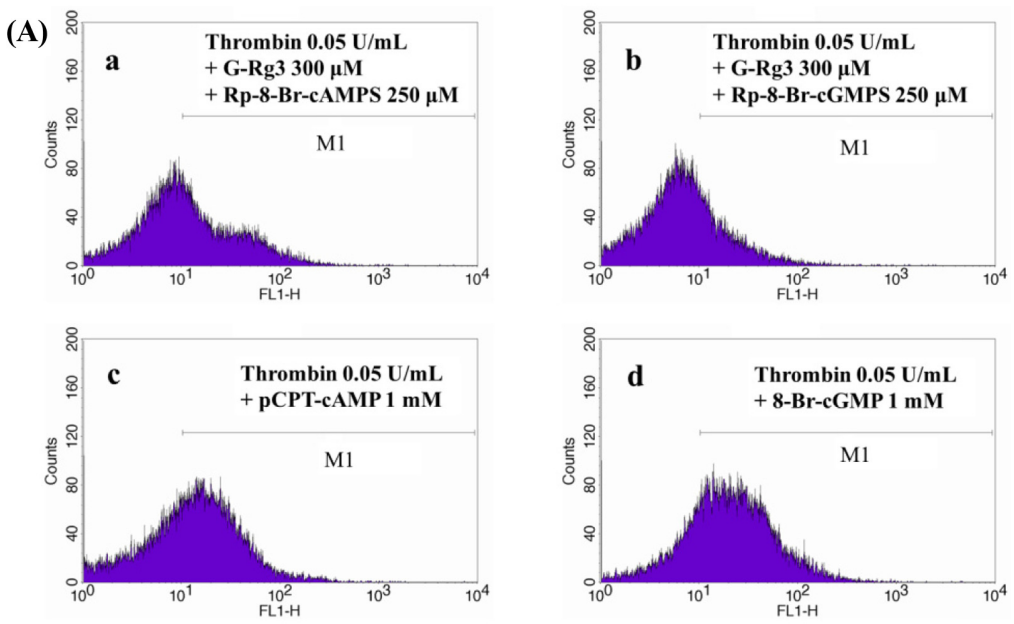

(B)

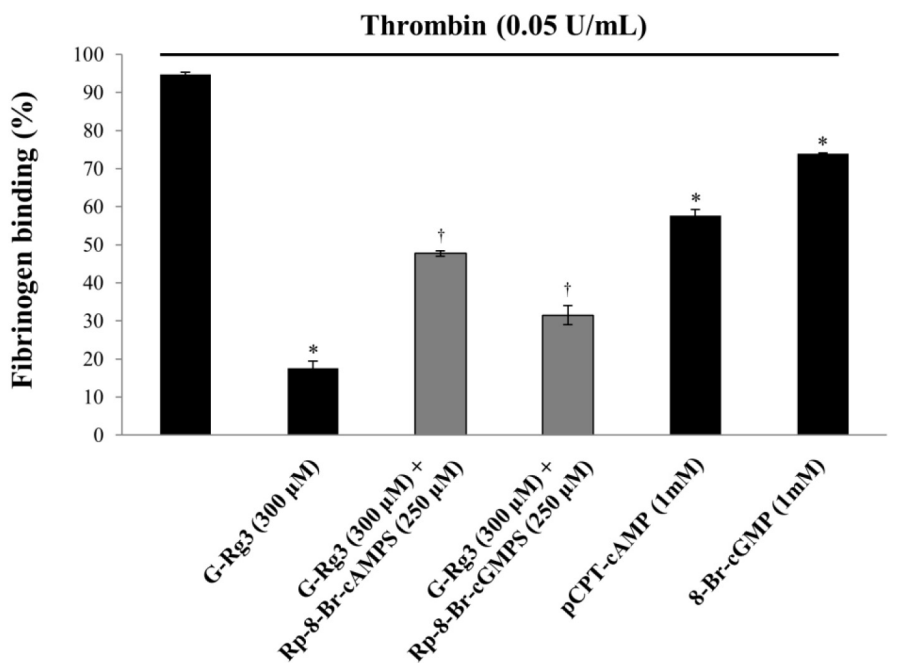

Fig. 5 Inhibitory effects of G-Rg3 on thrombin-induced fibrinogen binding in the presence of A-kinase inhibitor and G-kinase inhibitor. (A) The flow cytometry histograms on fibrinogen binding expression in the presence of Rp-8-Br-cAMPS and Rp-8-Br-cGMPS. a, Thrombin (0.05 U/mL) + G-Rg3 $(300 \mu \mathrm{M})+\mathrm{Rp}-8$-Br-cAMPS $(250 \mu \mathrm{M}) ; \mathrm{b}$, Thrombin $(0.05 \mathrm{U} / \mathrm{mL})+\mathrm{G}-\mathrm{Rg} 3(300 \mu \mathrm{M})+\mathrm{Rp}-8$-Br-cGMPS (250 $\mu \mathrm{M})$. (B) Effects of G-Rg3 on thrombin-induced fibrinogen binding in the presence of Rp-8-Br-cAMPS and Rp-8-Br-cGMPS (\%). Measurement of fibrinogen binding was described in "Materials and Methods" section. The data are expressed as the mean \pm standard deviation $(\mathrm{n}=4)$. * $p<0.05$ versus the thrombin-stimulated human platelets, ${ }^{\dagger} p<0.05$ versus the thrombin-stimulated human platelets in the presence of G-Rg3 $(300 \mu \mathrm{M})$

\section{Discussion}

Cardiovascular disease, which includes all diseases of the heart and blood vessels, is a leading cause of morbidity and mortality. Its major underlying pathology is atherosclerosis. Many studies have suggested that platelets have an important pro-inflammatory function in atherosclerosis [12]. The $\alpha$-granules within the platelets contain abundant chemokines, which increase vascular inflammatory responses [13]. Moreover, activated platelets bind with monocyte and vascular endothelium, elevating monocyte recruitment and accelerating atherosclerotic lesions development $[14,15]$. Therefore, therapeutic agents that inhibit platelets may mitigate the development of early stage atherosclerosis.

Our previous reports showed that Korean red ginseng extract increases cyclic AMPlevel in thrombin-activated rat platelets [16].
I also previously reported that the ginsenosides [Ra1, Rb1, Rb2, $\mathrm{Rb} 3$, Rc, Rd, and $\mathrm{Rh} 2$ (20R)] of the protopanaxadiol saponin group, as well as ginsenosides [Re, Rf, Rg1, Rg2 (20R), and Rh1 $(20 \mathrm{~S})]$ of the protopanaxatriol saponin group, do not affect human platelet aggregation. However, G-Ro and G-Rg3 (20S) exert suppression of human platelet aggregation [9]. Thus, in the present study, I first examined the effect of G-Ro on cyclic AMP concentration in human platelets and verified its cyclic AMPelevating effect [17]. The current study focused on the G-Rg3induced increase in cyclic AMP level. G-Rg3 attenuated the fibrinogen binding and fibronectin adhesion to $\alpha \mathrm{IIb} / \beta_{3}$ through VASP phosphoryaltion. VASP Ser ${ }^{157}$ and $\operatorname{Ser}^{239}$ are phosphorylated by cyclic AMP/A-kinase and cyclic GMP/G-kinase, respectively $[10,11]$. It was therefore concluded that G-Rg3 stimulated VASP Ser ${ }^{157}$ phosphorylation in a cAMP-dependent manner, but did not 

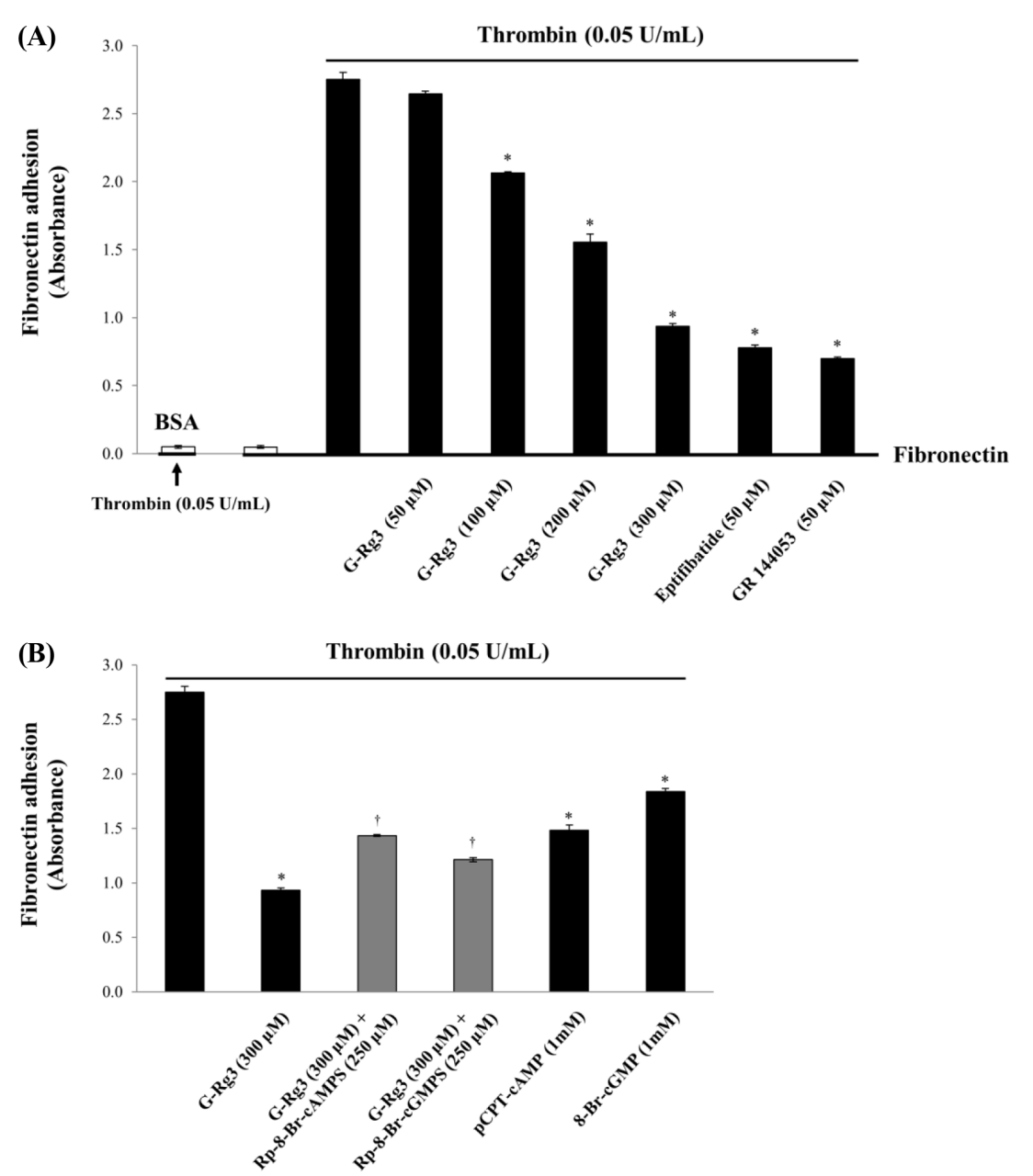

Fig. 6 Inhibitory effects of G-Rg3 on thrombin-induced fibronectin adhesion. (A) Inhibitory effects of G-Rg3 on fibronectin adhesion. (B) Effects of G$\mathrm{Rg} 3$ on thrombin-induced fibronectin adhesion in the presence of Rp-8-Br-cAMPS. Measurement of fibronectin adhesion was described in "Materials and Methods" section. BSA, bovine serum albumin (negative control). The data are expressed as the mean \pm standard deviation $(\mathrm{n}=4)$. ${ }^{*} p<0.05$ versus the thrombin-stimulated platelets, ${ }^{\dagger} p<0.05$ versus the thrombin-stimulated platelets in the presence of G-Rg3 $(300 \mu \mathrm{M})$

influence on $\operatorname{Ser}^{239}$ phosphorylation, as G-Rg3 influenced only the cyclic AMP levels (Table 1).

Clot retraction is the most crucial step in the repair and healing process of damaged blood vessels $[18,19]$. The clot formed by coagulation factors and activated platelets, is composed of fibrin and platelets. In the coagulation phase, both extrinsic and intrinsic pathways result in the generation of thrombin, which converts fibrinogen into the fibrin. At the same time, the activated platelets are accumulated in the damaged blood vessel, forming a fibrinplatelet mesh. Additional circulatory platelets and blood cells are trapped in mesh, accelerating clot formation. The clot, which seals off the damaged vessel, then begins to undergo retraction over a period of 30-60 minutes, pulling the cut edges of the vessel together. Since G-Rg3 strongly suppressed thrombin-induced clot retraction, it was suggested that the downregulation of $\alpha \mathrm{Ilb} / \beta_{3}$ by $\mathrm{G}-\mathrm{Rg} 3$ leads to the extension of clot retraction.

The G-Rg3 enriched faction from red ginseng inhibits collageninduced granule secretion, $\mathrm{p}$-selectin expression and fibrinogen binding [8]. The mechanism of G-Rg3 inhibitory effect on $\alpha \mathrm{IIb} /$ $\beta_{3}$ function was not clear, but our results suggested that this inhibitory effect was attributed cAMP/VASP $\operatorname{Ser}^{157}$ signaling pathway. Furthermore, it has been reported that antiplatelet compounds, such as Korean red ginseng extract, ginsenoside Rp1 and ginsenoside Ro increase cyclic AMP levels [16-17,20]. These reports also suggest that the inhibitory action of ginseng saponins on platelet activation might be caused by increased cyclic AMP levels. Recently, it has been reported that newly isolated ginseng saponins and metabolites (Rk1, Rk3, Rg5, Rg6, Rh4, Rs3, Rs4, Rs5, and F4) exert antiplatelet activities [21-23], but the mechanism is still unclear. Therefore, it will be investigated whether the new ginseng compounds on cyclic AMP level in human platelets.

In conclusion, our present study suggested that the affinity of fibrinogen and fibronectin with $\alpha \mathrm{IIb} / \beta_{3}$ was inhibited by G-Rg3 via cyclic AMP-dependent VASP Ser ${ }^{157}$ phosphorylation. Therefore, G-Rg3 may be used as a therapeutic agent for prevention of thrombosis and other platelet-mediated cardiovascular diseases. 
(A)

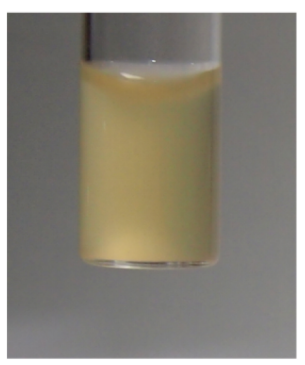

(B)

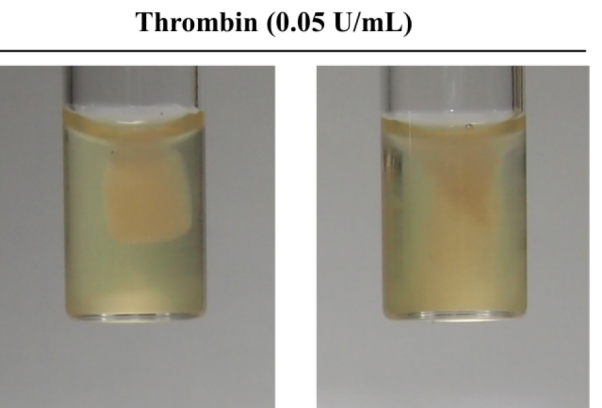

G-Rg3 (300 $\mu \mathrm{M})$

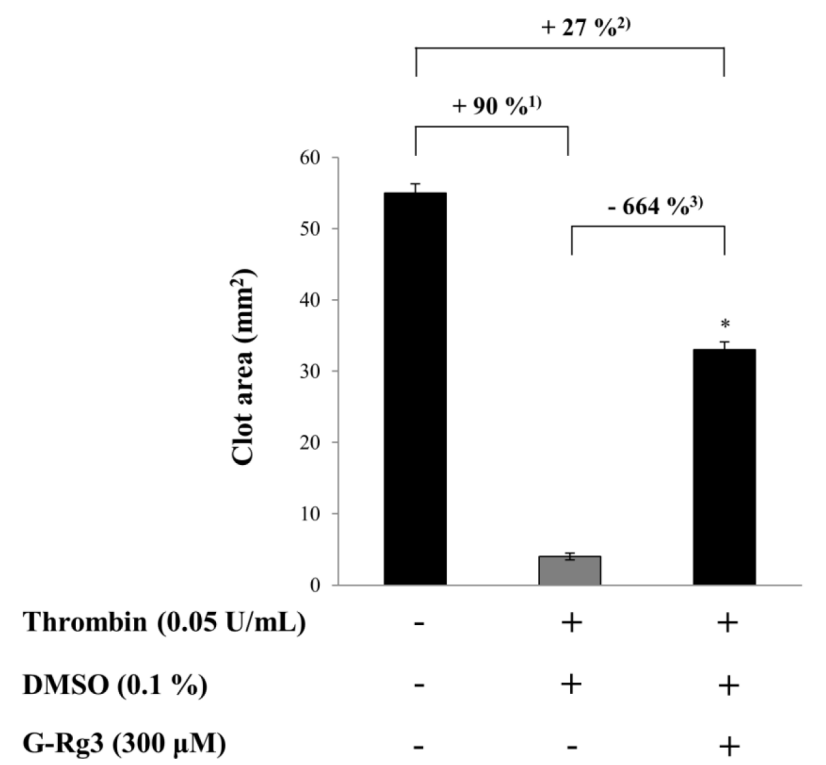

Fig. 7 Inhibitory effects of G-Rg3 on fibrin clot retraction. (A) Photographs of fibrin clot (B) Effects of G-Rg3 on thrombin-retracted fibrin clot. Quantification of fibrin clot retraction was described in "Materials and Methods" section. 1) $=($ base - thrombin $) /$ base $\times 100$. 2) $=[$ base (thrombin + G-Rg3)] / base $\times 100,3)=[$ thrombin $-($ thrombin + G-Rg3)] / thrombin $\times 100$. The data are expressed as the mean \pm standard deviation $(\mathrm{n}=4) . * p<0.05$ versus the thrombin-stimulated platelets

Acknowledgments This study was supported by a grant (NRF-20110012143 to Hwa-Jin Park) from the Basic Science Research Program via the National Research Foundation of Korea (NRF), which was funded by the Ministry of Education, Science and Technology, Korea

Conflict of interest The authors declare no conflict of interest.

\section{References}

1. Phillips DR, Nannizzi-Alaimo L, Prasad KS (2001) Beta3 tyrosine phosphorylation in alphaIlbbeta3 (platelet membrane GP IIb-IIIa) outside-in integrin signaling. Thromb Haemost 86: 246-258

2. Smolenski A (2012) Novel roles of cAMP/cGMP-dependent signaling in platelets. J Thromb Haemost 10: 167-176

3. Laurent V, Loisel TP, Harbeck B, Wehman A, Gröbe L, Jockusch BM, Wehland J, Gertler FB, Carlier MF (1999) Role of proteins of the Ena/ VASP family in actin-based motility of Listeria monocytogenes. J Cell Biol 144:1245-1258

4. Sudo T, Ito H, Kimura Y (2003) Phosphorylation of the vasodilatorstimulated phosphoprotein (VASP) by the anti-platelet drug, cilostazol, in platelets. Platelets 14:381-390
5. Matsuda H, Kubo M, Tani T, Arichi S, Kitagawa I (1985) Pharmacological Study on Panax ginseng CA MEYER V.: Effects of Red Ginseng on the Experimental Disseminated Intravascular Coagulation (4). On Ginsenoside-Rg3, Rh1 and Rh2. The Japanese Society of Pharmacognosy 39: 123-125

6. Lee SR, Park JH, Kim ND, Choi KJ (1997) Inhibitory effects of ginsenoside $\mathrm{Rg} 3$ on platelet aggregation and its mechanism of action. $\mathrm{J}$ Ginseng Res 21: 132-140

7. Lee WM, Kim SD, Park MH, Cho JY, Park HJ, Seo GS, Rhee MH (2008) Inhibitory mechanisms of dihydroginsenoside Rg3 in platelet aggregation: critical roles of ERK2 and cAMP. J Pharm Pharmacol 60: $1531-1536$

8. Jeong D, Irfan M, Kim SD, Kim S, Oh JH, Rhee MH (2017) Ginsenoside $\mathrm{Rg} 3$-enriched red ginseng extract inhibits platelet activation and in vivo thrombus formation. J Ginseng Res 41: 548-555

9. Shin JH, Kwon HW, Cho HJ, Rhee MH, Park HJ (2015) Inhibitory effects of total saponin from Korean Red Ginseng on $[\mathrm{Ca} 2+] \mathrm{i}$ mobilization through phosphorylation of cyclic adenosine monophosphatedependent protein kinase catalytic subunit and inositol 1,4,5trisphosphate receptor type I in human platelets. J Ginseng Res 39: 354 364

10. Smolenski A, Bachmann C, Reinhard K, Hönig-Liedl P, Jarchau T, Hoschuetzky H, Walter U. (1998) Analysis and regulation of vasodilator- 
stimulated phosphoprotein serine239 phosphorylation in vitro and in intact cells using a phosphor specific monoclonal antibody. J Biol Chem 273: 20029-20035

11. Barragan P, Bouvier JL, Roquebert PO, Macaluso G, Commeau P, Comet B, Eigenthaler M (2003) Resistance to thienopyridines: Clinical detection of coronary stent thrombosis by monitoring of vasodilatorstimulated phosphoprotein phosphorylation. Catheter Cardiovasc Interv 59: $295-302$

12. Jackson SP (2011) Arterial thrombosis - insidious, unpredictable and deadly. Nature medicine 17: 1423-1436

13. Jennings LK (2009) Role of platelets in atherothrombosis. Am J Cardiol 103: 4A-10A

14. Zarbock A, Polanowska-Grabowska RK, Ley K (2007) Plateletneutrophil-interactions: linking hemostasis and inflammation. Blood reviews 21: 99-111

15. Davì G, Patrono C (2007) Platelet activation and atherothrombosis. New Engl J Med 357: 2482-2494

16. Lee DH, Cho HJ, Kim HH, Rhee MH, Ryu JH, Park HJ (2013) Inhibitory effects of total saponin from Korean red ginseng via vasodilator-stimulated phosphoprotein-Ser157 phosphorylation on thrombin-induced platelet aggregation. J Ginseng Res 37: 176-186

17. Kwon HW, Shin JH, Lee DH, Park HJ (2015) Inhibitory Effects of Cytosolic $\mathrm{Ca} 2+$ Concentration by Ginsenoside Ro Are Dependent on
Phosphorylation of IP3RI and Dephosphorylation of ERK in Human Platelets. Evid-Based Compl Alt. doi:10.1155/2015/764906

18. Law DA, DeGuzman FR, Heiser P, Ministri-Madrid K, Killeen N and Phillips DR (1999) Integrin cytoplasmic tyrosine motif is required for outside-in $\alpha \operatorname{IIb} \beta 3$ signalling and platelet function. Nature 401: 808-811

19. Estevez B, Shen B and Du X (2015) Targeting Integrin and Integrin Signaling in Treating Thrombosis. Aterioscl Throm Vas 35: 24-29

20. Endale M, Lee WM, Kamruzzaman SM, Kim SD, Park JY, Park MH, Park TY, Park HJ, Cho JY, Rhee MH (2012) Ginsenoside Rp1 inhibits platelet activation and thrombus formation via impaired glycoprotein VI signalling pathway, tyrosine phosphorylation and MAPK activation. Br J Pharmacol 167: 109-127

21. Lee JG, Lee YY, Kim SY, Pyo JS, Yun-Choi HS, Park JH (2009) Platelet antiaggregating activity of ginsenosides isolated from processed ginseng. Die Pharmazie-Int J Pharm Pharm Sci 64: 602-604

22. Lee JG, Lee YY, Wu B, Kim SY, Lee YJ, Yun-Choi HS, Park JH (2010) Inhibitory activity of ginsenosides isolated from processed ginseng on platelet aggregation. Die Pharmazie-Int J Pharm Pharm Sci 65: 520-522

23. Ju HK, Lee JG, Park MK, Park SJ, Lee CH, Park JH, Kwon SW (2012) Metabolomic investigation of the anti-platelet aggregation activity of ginsenoside Rk1 reveals attenuated 12-HETE production. J Proteome Res 11: 4939-4946 